\title{
Multiculturalismo y educación intercultural: análisis comparativo de cuatro autobiografías de minoría étnica en Estados Unidos
}

\author{
Georges Moukouti Onguedou \\ Université de Maroua \\ moukouti@yahoo.fr
}

ResUM

Multiculturalisme i educació intercultural: anàlisi comparativa de quatre autobiografies de minoria ètnica als Estats Units

Parlar de multiculturalisme i d'educació intercultural és inscriure's en una dinàmica de coexistència i d'obertura cap a l'Altre. En aquesta perspectiva analitzem Black Boy de Richard Wright, $A$ Walker in the City d'Alfred Kazin, The Woman Warrior de Maxine Hong Kinston i Hunger of Memory de Richard Rodríguez, quatre obres autobiogràfiques de minoria ètnica als Estats Units. Partim de l'observació segons la qual els nostres pobles en particular i el món en general són multiculturals, ja que diferents cultures solen cohabitar en un mateix espai. Com a conseqüència, es planteja el problema de la interrelació entre els diferents grups ètnics-culturals i la qüestió de les identitats.

Paraules clau

Autobiografia, Educació intercultural, Identitats, Minoria ètnica, Multiculturalisme.

RESUMEN

Multiculturalismo y educación intercultural: análisis comparativo de cuatro autobiografías de minoría étnica en los Estados Unidos

Hablar de multiculturalismo y de educación intercultural es inscribirse en una dinámica de coexistencia y de apertura con y hacia al Otro. Desde esta perspectiva analizamos Black Boy de Richard Wright, $A$ Walker in the City de Alfred Kazin, The Woman Warrior de Maxine Hong Kinston y Hunger of Memory de Richard Rodríguez, cuatro obras autobiográficas de minoría étnica en los Estados Unidos. Partimos de la observación según la cual nuestros pueblos en particular y el mundo en general son multiculturales, pues diferentes culturas suelen cohabitar en un mismo espacio. De resultas, se plantea el problema de la interrelación entre los diferentes grupos étnico-culturales y la cuestión de las identidades.

Palabras clave

Autobiografía, Educación intercultural, Identidades, Minoría étnica, Multiculturalismo.

RÉSUMÉ

Multiculturalisme et éducation interculturelle : analyse comparative de quatre autobiographies de minorité ethnique aux Etats-Unis

Parler de multiculturalisme et d'éducation interculturelle revient à s'inscrire dans une dynamique de coexistence et d'ouverture avec et à l'Autre. C'est dans cette perspective que nous analysons 
Black Boy de Richard Wright, $A$ Walker in the City de Alfred Kazin, The Woman Warrior de Maxine Hong Kingston et Hunger of Memory de Richard Rodríguez, quatre ouvres autobiographiques de minorité ethnique aux Etats-Unis. Nous partons du constat que nos pays en particulier et le monde en général sont multiculturels, puisque différentes cultures se côtoient dans un même espace. Et du coup, se pose le problème de l'interrelation entre les différents groupes ethnico-culturels et la question des identités.

\section{MoTS CLÉS}

Autobiographie, Education interculturelle, Identités, Minorité Ethnique, Multiculturalisme.

\section{Abstract}

\section{Multiculturalism and intercultural education: comparative study of four autobiographies on ethnic minority in the United States}

Talking about multiculturalism and intercultural education means to take part in a dynamic coexistence and openness with and to the Other. It is in this perspective that we fundamentally analyse Richard Wright's Black Boy, Alfred Kazin's A Walker in the City, Maxine Hong Kingston's The Woman Warrior and Richard Rodríguez's Hunger of Memory, four autobiographies on ethnic minority in the United States. We depart from the observation that our people in particular and the world in general are multicultural: different cultures often coexist in the same space. Consequently, the problem of the interrelationship between ethno-cultural groups and the question of identities is raised.

\section{KeYwords}

Autobiography, Ethnic minority, Identities, Intercultural Education, Multiculturalism.

\section{Introducción}

Por esencia Estados Unidos es un país multicultural, donde conviven varias culturas que se ven reflejadas en su multilingüismo porque, de concierto con Shohat y Stam (1994), "America began as poliglot and multicultural, speaking a myriad of languages: European, African and Native American" (4). Hablar de Black Boy (2007) de Richard Wright, A Walker in the City (1979) de Alfred Kazin, The Woman Warrior (1977) de Maxine Hong Kingston y Hunger of Memory (1982) de Richard Rodríguez es hablar de cuatro autobiografías de minorías étnico-culturales en Estados Unidos: la afro-estadounidense, la judeo-estadounidense, la sino-estadounidense y la mexicanoestadounidense, respectivamente. Se trata de cuatro "bildunsromans" o novelas de iniciación; de cuatro novelas cuyas historias están contadas en unas retrospectivas primeras personas por narradores adultos que vuelven la mirada hacia su pasado (Borrego Silva, 2002); de cuatro relatos retrospectivos en prosa hechos por personas reales sobre sus propias existencias, poniendo acento sobre sus vidas individuales, en particular sobre la historia de sus personalidades (Lejeune, 1996); de cuatro novelas donde los protagonistas-narradores se fraguan una identidad multicultural. El recurso a las marcas de la primera persona del singular (I, me, my) reenvía aquí a un Yo en busca de una autodeterminación. Para alcanzar la dimensión multicultural e intercultural de estas autobiografías, 
partiendo obviamente del pacto autobiográfico ${ }^{1}$, exploramos primero la infancia, las circunstancias familiares o sociales, la adolescencia y la ruptura de los proyectos identitarios de cada Yo que escribe, narra y actúa. Luego analizamos la estructura y la temática de cada obra con vistas a alcanzar la profecía auto cumplidora para cada protagonista antes de establecer, en última instancia, el paralelo entre las cuatro autobiografías.

\section{Infancia, circunstancias familiares o sociales, adolescencia y ruptura de los proyectos identitarios}

Empezar por la niñez del Yo escritor, narrador y protagonista de cada una de estas autobiografías implica inherentemente volver a sus primeros pasos en la vida. De modo cronológico, Richard Nathaniel Wright nace el 4 de septiembre de 1908 entre los paupérrimos del Estado racista y segregacionista del Misisipí, en la ciudad de Natchez que en el siglo XIX era el gran mercado de esclavos del sur estadounidense. El 5 de junio de 1915, nace Alfred Kazin. Hijo de inmigrantes judíos procedentes de Rusia, habla "Yiddish" en casa. Como Richard Wright, aunque a escala desigual, es de familia pobre. Vive en Brownsville (Nueva York), entre muchos judíos, la mayoría de ellos hijos de obreros inmigrantes. Treinta y seis años después de Richard Wright llega a la vida la sino- estadounidense Maxine Hong Kingston, el 27 de octubre de 1940, bajo el nombre de Maxine Ting Ting Hong. Hermana mayor de los seis hijos que tienen sus padres en Stockton (California), vive enraizada en la cultura china. El 31 de julio de 1944 nace en México Richard Rodríguez. Emigra a los cinco años con su familia a California. Ricky Rodríguez habla español en casa hasta que entra en la escuela católica a los 6 años.

Entrando en las obras - prosas líricas - descubrimos a protagonistas-narradores cuyas vidas se parecen a las de los escritores Wright, Kazin, Kingston y Rodríguez. En Black Boy, todo empieza con un Richard Wright que, a los 4 años, pone fuego a la casa familiar. A partir de este momento comienzan los vaivenes y las peripecias para encontrar un techo. En su educación, Richard es abandonado a su suerte. Es alcohólico a los 6 años, pero sorprendentemente termina manifestando una sed por la lectura. Cuando supera su dependencia del alcohol, entra en los internados y las escuelas. La parálisis de su madre los obliga a ir a casa de sus abuelos. Sin mucho apoyo de su familia, Richard tiene que arreglárselas para salir adelante. Por ser cada vez pegado, acaba rebelándose, amenazando incluso a sus tíos con un cuchillo. En su último año escolar, escribe su primera historia que publica un periódico de la ciudad. Con la calificación que recibe durante ese último año de clase, le dan el honor de pronunciar el discurso para el término del año.

En $A$ Walker in the City, se describen los años de infancia y adolescencia del autor, cuando su deseo de aprender lo conduce a las bibliotecas y a las calles de Nueva York. Andando (walking) se convierte en un proceso de exploración y adquisición de conocimientos. Se trata de una metáfora

\footnotetext{
1. En una autobiografía, el pacto autobiográfico (Lejeune, 1996) consiste en un acuerdo implícito entre el escritor y el lector respecto del contenido de la obra. Se trata precisamente para el lector de pensar que lo relatado es indiscutiblemente la vida del autor; y que este último, el narrador y el protagonista representan la misma identidad. Se confunden el que escribe el libro (autor), el que relata la historia (narrador) y el que actúa (personaje). Esto significa que las tres principales representaciones llevan el mismo nombre. Lo que induce forzosamente el uso de la primera persona: el "yo" que escribe, relata y actúa. Sin embargo, no se trata de considerar la autobiografía como un relato fiel de las vivencias del autor, siendo cualquier obra literaria el producto de la imaginación; por lo que, al relatar sus vivencias, el autor puede distorsionarlas, pues, el autobiógrafo suele contar lo que quiere que se retenga de él.
} 
de un viaje espiritual e intelectual que empieza desde su temprana niñez y se dilata luego en su adolescencia; todo eso tapizado con los eventos como son la Primera Guerra Mundial y la Gran Depresión de 1929. El Yo Kazin nutre también una pasión vitalicia por la lectura, la cual pasión se va a desarrollar con la literatura, como lo confiesa en el capítulo cuatro: "nevertheless I still thought of myself then as standing outside America. I read as if books would fill my every gap, legitimize my strange quest for the American past, remedy my every flaw, let me in at last into the great world that was anything just out of Brownsville" (Kazin, 1979:172). Su padre es pintor de brocha gorda y simpatizante del partido socialista. Kazin aprende, crece y experimenta todo en su entorno. Está en un proceso de asimilación que no significa una integración forzada en los moldes sociales existentes, sino un proceso activo. No solamente está absorto por América, sino que también absorbe el mundo de su entorno, dejando sus propias marcas culturales.

Kingston, en The woman warrior, se recrea en la China de sus orígenes. Se trata de un lugar de todos los peligros y de obstáculos contra la mujer. Eso cristaliza las angustias de la heroína, inmigrante de la segunda generación en los EE.UU. Exorcizando sus angustias y miedos, la heroína no está lejos de rechazar su herencia cultural, sobre todo por confundir lo chino y lo estadounidense: "Chinese-Americans, when you try to understand what things in you are Chinese, how do you separate what is peculiar to childhood, to poverty, insanities, one family, your mother who marked your growing with stories, from what is Chinese? What is Chinese tradition and what is the movies" (Kingston, 1977:13).

Hunger of Memory: The Education of Richard Rodríguez trata de una narración sobre el desarrollo del Yo Rodríguez como estudiante norteamericano y literato. Retrata a este niño que está luchando para ser un hombre en la sociedad estadounidense. La obra abre una reflexión sobre la importancia de una lengua como es el inglés en los EE.UU., la acción afirmativa / positiva, la educación bilingüe, la identidad privada y pública.

\section{Hacia la profecía auto cumplidora del Yo escritor, narrador y protagonista}

La profecía auto cumplidora, expresión empleada por Castilla del Pino (1989) en relación con la identidad, remite a la frustación del adolescente respecto de unas expectativas entre él y los adultos y su grupo social. Este crítico piensa que con frecuencia "es justamente en la adolescencia cuando acontece la ruptura del proyecto de identidad que hasta entonces los adultos le habían conferido: el adolescente impone entonces su identidad, y el pacto ulterior o se hace sobre una identidad o por ambos se rompe la relación" (28). En esta parte, hablar de la profecía auto cumplidora del Yo escritor, narrador y protagonista nos obliga a pasar por la estructura y la temática de estas autobiografías.

Con una estructura lineal y cronológica en catorce capítulos, sin alteración del orden temporal y secuencial, la obra de Richard Wright empieza con un capítulo I que marca la vida del autor, una vida de violencia, sobre todo una violencia familiar. En el capítulo II, los padres de Richard se divorcian. El padre, alcohólico, abandona la casa y el niño empieza a pasar hambre. Del fanatismo religioso de la abuela de Richard es cuestión en el capítulo III, mientras que en el cuarto, se vuelve a hablar de la violencia con su tía Addie. Ya en el capítulo V, Richard quiere trabajar para sobrevivir, pero su abuela se lo impide. En el capítulo VI, el niño acompaña a su madre a la iglesia y experimenta la falsedad de la religión que, en este libro, parece frustrarlo. En un primer momento, Richard va a complacer a su madre y a su comunidad: 
It was no longer a question of believing in God; it was no longer a matter of whether I would steal or lie or murder; it was a simple, urgent matter of public pride, a matter of how much I had in common with other people. If I refused, it meant that I did not love my mother, [...] no barriers now stood between me and the community (2007: 154-155).

Sin embargo, a pesar de los lazos familiares y comunitarios y de la importancia de la religión para los afro-estadounidenses, Richard se rebela luego y se niega a ser bautizado en esa iglesia.

En el capítulo VII, se trata de la afirmación de Richard como individuo, y esta autoafirmación es una lucha contra corriente. Los capítulos VIII y IX hablan del racismo y de la Guerra Civil. Los últimos capítulos hablan de Richard que huye hacia Chicago y que ve revelarse su hambre por la cultura. Se considera a sí mismo superior gracias a los libros. Con esta huida hacia el norte, Richard se distancia, dejando el sur. Pero desde este norte, no puede dejar de mirar el sur, pues en la mayoría de las autobiografías, los viajes son también regresos hacia la infancia, hacia el lugar y el tiempo de la infancia.

Como se puede notar, las letras y la cultura son muy importantes en las autobiografías de esclavos, como lo son también para las minorías étnicas. Ayudan al individuo a liberarse. Con el caso particular de los esclavos, permiten deshacerse del yugo de los amos. En esas narraciones de esclavos como es Black Boy, existen temas como el racismo con sus corolarios (la opresión del mundo blanco sobre el negro, la crueldad de los amos, la violencia física, el hambre y la miseria, etc.), la cultura mediada por la literatura (pero los obstáculos son las dificultades para acceder a los libros). También se suele asistir a un intento de huida que termina por un escape feliz hacia el simbólico lugar que es el norte. Los temas de la religión (como opio del pueblo), la alienación, la familia y la comunidad están también presentes.

A partir de unos aspectos narrativos y estilísticos de la obra, se puede observar que el autor utiliza con frecuencia metáforas (por ejemplo con el uso de la naranja o del norte como símbolos del hambre y de la felicidad, respectivamente). Los capítulos VI y VII están cargados de ironías que aquí sirven para retratar el fundamentalismo religioso de la tía que quiere convertir al niño en Adventista del Séptimo Día y su madre, en Metodista.

La autobiografía de Richard Wright celebra, como es el caso de la mayoría de los autobiógrafos masculinos, la figura de la madre. Además, con esta figura de la madre, el autor se vale de la estrategia del otro, la cual se refleja con el sufrimiento de su genitora: "My mother's suffering grew into a symbol in my mind, gathering to itself all the poverty, the ignorance, the helplessness; the painful, baffling, hunger-ridden days and hours; [...] a conviction that the meaning of living came only when one was struggling to wring a meaning out of meaningless suffering" (2007: 98-99).

A diferencia de Black Boy, $A$ Walker in the City de Alfred Kazin tiene una estructura fragmentada, en cuatro capítulos. Son cuatro ensayos separados, con un principio y un fin, dos tiempos (el pasado y el presente). Con el presente, Kazin aparece como un niño o adolescente caminante (capítulos 1 y 3) mientras que el pasado nos presenta a un Kazin como escritor (capítulos 2 y 4). Existen aquí dos personajes literarios: el niño, que va por las calles de la ciudad y el adulto, que regresa por esas calles de la ciudad. Toda la trama del texto se estructura en dos ejes espaciales diametralmente opuestos: Brownsville (que en los años treinta ya era un barrio de inmigrantes y pobres) y Manhattan (barrio de los blancos y ricos). Los dos barrios están separados por el puente (the Bridge).

En el primer capítulo, "From the Subway to the Synagogue", Kazin habla de su infancia, tras su traslado a Brownsville. El personaje caminante y niño se encuentra paseando por esas calles de Brownsville que, a pesar de ser un espacio, se convierten en esencia de toda una vida. El segundo 
capítulo, "The Kitchen" aparece como la metáfora de la vida de la madre y su trabajo suplementario en casa: "The kitchen gave a special character to our lives; my mother's character. All my memories of that kitchen are dominated by the nearness of my mother sitting all day long at her sewing machine" (1979: 66). En "The Block and Beyond”, Kazin hace alusión a los idiomas. En una conversación en francés con Mrs. Solvery, el autor deja captar la importancia de la lengua y de la cultura como médium que permita escaparse y acceder a un nivel superior, tal como piensan Richard Rodríguez y Richard Wright. En el último capítulo, "Summer: The Way To Highland Park", penetramos en la sicología de Kazin como adolescente, pues su vida se nos ofrece como un pasaje ritual. Aquí, no tenemos un fin en la medida en que el viaje o el caminar se parecen a continuar.

De manera general, en $A$ Walker in the City hay tres voces (el caminante, el niño y el escritor) que nos ofrecen la historia, o mejor la memoria de una infancia en Brownsville (Brooklyn): la vecindad (neighborhood), los almacenes judíos (Jewish stores), la biblioteca (the public library), los cines del centro de la ciudad, etc. Como adolescente (teenager), Kazin tiene la costumbre de espiar las torres de Manhattan, desde el río de Brooklyn, torres que son símbolos de la vida pública. Esta obra es también la vida en la ciudad, con todos los personajes que en la ciudad podemos encontrar.

Como en Hunger of Memory de Richard Rodríguez, Kazin utiliza también los pronombres oposicionales "they, them" para referirse a los blancos y "us" para nosotros, es decir, "I" y los suyos: "Why did they live there and we always in "Brunzvil"? Why were they there, and we always here? Why was it always them and us, Gentiles and us, alrightniks and us" (1979: 98-99). Además, notamos el uso de dos adverbios que se oponen espacialmente: "there" (Manhattan) y "here" (Brownsville).

Los temas de la religión (judía), el amor, la literatura, la cultura (judía), la educación, la soledad, la alienación cultural, la asimilación, el sentimiento racial, la pobreza, la nostalgia, etc. se leen mediante figuras estilísticas como la repetición, la metáfora y la sinécdoque. Por ejemplo, con el uso repetitivo de "I miss", Kazin está listando, de forma nostálgica, todo lo que ha perdido. En efecto, esta autobiografía es un acto de reconciliación con el mundo que ya no existe. La nostalgia aquí se convierte en rabia por la conciencia de lo que se ha perdido:

[...] and to my amazement I miss her old, sly, and withered face. I miss all those ratty little wooden tenements,[...] I miss that affected squirt who always wore a paste diamond on his left pinky and one unforgotten day, taught me to say children for kids; I miss the sinister Coney Island dives where before, during, and after the school day we all anxiously gobbled down hot dogs soggy in sauerkraut and mustard, ...I miss the poisonous sweetness [...] I miss the liturgical refrain [...] (1979:13).

$\mathrm{Al}$ emprender su acto autobiográfico, Kazin materializa su intención de cruzar el puente y romper con las barreras entre los dos lados del puente. Tanto Kazin como Richard Rodríguez son muy ambivalentes acerca del tema de la religión y la asimilación cultural. Y es que celebran su asimilación como hombres estadounidenses, pero al mismo tiempo sienten una nostalgia hacia lo perdido. Por ejemplo, Kazin nunca había leído la Biblia en hebreo, pero sí la lee en inglés. Ambos autores manifiestan el sentimiento estadounidense por la lengua inglesa, con la diferencia de que Kazin siente también el orgullo de ser judío.

Como en Hunger of Memory, $A$ Walker in the City presenta a un hombre intelectual, asimilado, que ha alcanzado el éxito del hombre estadounidense y lo que ha ganado y perdido de su asimilación como tal: 
I was the first American child, their offering to the strange new God; I was to be the monument of their liberation from the shame of being- what they were. And that there was shame in this was a fact that everyone seemed to believe as a matter of course. It was in the gleeful discounting of themselveswhat do we know?- with which our parents greeted every fresh victory in our savage competition for "high averages", for prizes, for a few condescending words of official praise from the principal at assembly (1979:23-24).

También habla de la dicotomía entre el legado cultural y lingüístico. Con todo, Kazin el niño tiene que triunfar en este país, por eso necesita dejar detrás cosas y cruzar el puente y llevar así la carga que sus padres han puesto en él.

En la autobiografía The Woman Warrior: Memoirs of a Girlhood among Ghosts (1977), Kingston incorpora muchos elementos de ficción, mitología, historia, leyendas y lírica. Explora la etnicidad, la raza, la cultura, la pobreza y los problemas de género, especialmente en su caso como mujer estadounidense de raíces chinas. Su texto es un viaje hacia su infancia y un discurso subversivo contra el silencio. Dividida en cinco capítulos, esta obra de Kingston tiene una estructura circular y fragmentada, pues, los distintos relatos vienen yuxtapuestos y solamente conectados por la voz narrativa principal, y eso obliga al lector a participar en la construcción del relato, llenando los vacíos dejados adrede por la autora como consecuencia de una estética y una filosofía chinas sobre el vacío.

En el primer capítulo "No Name Woman", la autora describe el suicidio de su tía después de haber dado a luz a un niño ilegítimo en una China patriarcal. Considera a su tía como un ejemplo de subversión hasta identificarse con ella: "My aunt haunts me- her ghost drawn to me because now, after fifty years of neglect, I alone devote pages of paper to her, [...]. I am telling on her, and she was a spite suicide, drowning herself in the drinking water. [...]" (1977:22). Mediante esta "mujer sin apellido", Kingston manifiesta un acto de rebelión y desobediencia, y cuenta lo que su madre le presenta como prohibición.

En "White Tigers", la autora crea una fantástica alegoría en la que describe su infancia. Se imagina ella misma como una Fa Mu Lan, mujer guerrera china, legendaria e independiente. Con la simbólica de la mujer guerrera, tenemos estas funciones metonímica y denominadora del título (The Woman Warrior) y que no está lejos de convertir la obra en epónima.

En "Shaman", relata la experiencia de su madre en una escuela médica china. Mezcla la fantasía y la biografía describiendo los combates físicos y mentales de su madre contra los espíritus y fantasmas. En efecto, se trata de la biografía de su madre (la "chamán" o curandera y también guerrera) que ya dejó su oficio una vez llegada a EE.UU. En este capítulo es donde la heroína se enfrenta brutalmente a su madre, revelándole todos los agravios que ésta le ha causado. Buena muestra de esta discordia es el uso repetitivo de la negación "I don't":

[...], I don't get sick. I don't go to the hospital every holiday. I don't get pneumonia, [...]. And I don't get headaches at three o'clock. I don't have to take medicines or go to doctors. Elsewhere I don't have to lock my doors and keep checking the locks. I don't stand at the windows and watch for movements and see them in the dark [...] I don't want to hear Wino Ghosts and Hobo Ghosts (1977:100-101).

Si este tercer capítulo se centra en la imagen de la madre, en la discordia entre la madre y la heroína y el regreso de la última para hacer las paces, el cuarto capítulo, "At the Western Palace", describe la depresión mental de Moon Orchid, su tía, después de emigrar de China para los EE.UU. 
La reflexión aquí es que es una absurdez pensar trasplantar las cosas de China en Estados Unidos o las de Estados Unidos en China.

En el último capítulo, "A Song for a Barbarian Reed Pipe", Kingston describe su infancia en el sistema educativo público en California, así como la actitud de sus padres hacia ella. Además, se representa en una autoconfrontación ("self-confrontation") con una niña en la escuela, pero todo lo que experimenta en esa niña es un mero reflejo de sí misma: una chica callada, que no puede hablar. Este capítulo reviste un carácter simbólico, pues es un intento de amalgamar una doble identidad y traduce el dolor producido por el silencio. Por lo tanto, hay que romper este silencio para no seguir callando y celando secretos.

Cada capítulo tiene como punto de arranque una narración (mito, leyenda, fábula o relato de la vida) que la heroína ha oído en su infancia y en cada narración está un personaje femenino. De manera general, la novela de Kingston se desarrolla entre la leyenda (repetitiva y colectiva) y la ficción (creativa e individual), el realismo y la utopía, la violencia y la reconciliación, el tabú y el desvelamiento del secreto o la trasgresión de lo prohibido, pues todo empieza por la confiscación de la palabra, la imposibilidad de decir: "You must not tell anyone" (1977:11).

Partiendo de las técnicas narrativas, tenemos un texto tremendamente multivocálico, pues, asistimos a una narración de historias desde círculos muy amplios del Yo que se describe a través de otros personajes. Nos atenemos a dos protagonistas a los que la escritora permite dialogar en su obra, ofreciendo así el punto de vista de la hija como contrapunto del de la madre, pero lo que es la madre (y otro personaje del texto) es el retrato de la propia heroína; de ahí, la estrategia del otro, que también encontramos en Richard Wright. Aquí, cabe precisar que la heroína recibe las más de las veces informaciones de segunda mano; la China de la obra no existe como entidad identificable. La heroína la conoce a partir de los relatos de su madre, las leyendas aprendidas en su infancia, historias oídas en su Chinatown estadounidense. La importancia del personaje de la madre descarta aquí el sentimiento de matrofobia, como ocurre en la mayoría de las autobiografías femeninas.

En la obra abundan figuras de imagen como las metáforas y las analogías. Tenemos por ejemplo esta imagen del pájaro que vuela y la niña que intenta transgredir las leyes:

The call would come from a bird that flew over our roof. In the brush drawings it looks like the ideograph for "human", two black wings. The bird would cross the sun and lift into the mountains (which look like the ideograph "mountain"), there parting the mist briefly that swirled opaque again. I would be a little girl of seven the day I followed the bird away into the mountains (1977: 26).

Pese a intentar transgredir leyes, el Yo se da cuenta de que su herencia cultural forma parte de su personalidad; y al final de la obra, parece decirnos que ha elegido el "consent", es decir ser estadounidense. Pero con la acuñación de este relato lleno de leyendas de su pueblo, manifiesta su viaje hacia el "descent", la China de sus orígenes. De todas formas, entiende que su existencia tiene sentido sólo en una relación entre las dos identidades; de ahí que se pueda hablar de una identidad sobre la relación en vez de una identidad sobre la raíz, coincidiendo así con W. Boelhower que, respecto de la autobiografía étnica y de inmigrantes, piensa que "In this context, relational fluency, or the positive ability to move back and forth between the two different semiotic intentionalities of descent and consent, is foremost" (1991:131). El suicidio de "la mujer sin apellido" y el mutismo doloroso de la alumna sino-estadounidense no son vanos. En efecto, si dejan pensar en el fracaso de un sistema o modo de hacer, encierran también gérmenes y posibilidad de un cambio, el principio de una nueva era caracterizada por otra forma de ser y pensar. La heroína, después de perder sus raíces, 
puede a pesar de todo ver el mundo desde una perspectiva nueva, sin sentir miedo ni hostilidad, pues ya ha alcanzado la plenitud y la serenidad, porque "[...] Inside the clouds — inside the dragon's breath- I would not know how many hours or days passed. Suddenly, without noise, I would break clear into a yellow, warm world. New trees would lean toward me at mountain angles, but when I looked for the village, it would have vanished under the clouds" (1977: 26).

Hunger of memory en cuanto a ella tiene una estructura fragmentada (en seis capítulos y un prólogo), inconexa, con flash-backs, al igual que la estructura de autobiografías femeninas como la de Maxine Kingston. Fragmentada porque cada capítulo es un fragmento de su vida. También, tiene la obra una estructura circular, pues todo empieza en familia y acaba en familia. En el prólogo "Middle-Class Pastoral", el autor hace una justificación de su acto de escribir. Este libro es, en realidad, un acto político: "[...] My book is necessarily political, in the conventional sense, for publics issues" (1982: 5). El primer capítulo "Aria”, Richard Rodríguez habla de su infancia y de su proceso de asimilación. "The Achievement of Desire" remite a su educación mientras que "Credo" es un capítulo dedicado a la religión católica que concretamente ha contribuido a relacionar la vida privada y pública de Richard: "The Catholic Church of my youth mediated with special grace between the public and private realms of my life [...] That Church is no longer mine" (1982: 116).

En "Complexion", Rodríguez habla de los problemas relacionados con la discriminación racial (color), social y étnica: "Dark skin was for my mother the most important symbol of a life of oppressive labour and poverty" (1982:127). En "Profession", Richard justifica las decisiones profesionales que está tomando; y eso en relación con su pertenencia a una minoría étnica en los Estados Unidos. En el último capítulo "Mr. Secrets", Richard habla de su familia y de todos los secretos familiares (que son temas privados) que ha ido desvelando públicamente: "Today I can address an anonymous reader. And this seems to me important to say. Somehow the inclination to write about my private life in public is related to the ability to do so. It is not enough to say that my mother and father do not want to write their autobiographies" (1982:204).

La narración se centra en la experiencia de Richard Rodríguez frente a la separación de su familia, su alienación personal y finalmente su asimilación dentro del sistema social dominante en los Estados Unidos: deja detrás de él el español, lengua de su niñez, y entra en el inglés, idioma públicamente hablado en el país donde vive. Otros temas como la etnicidad, el orgullo estadounidense, la cultura y la historia de inmigrantes son también evocados en la obra. Rodríguez tiene conciencia del contraste entre la vida privada de la casa y la pública de la escuela. Realiza en el acto que para tener éxito en un campo, hay que aislarse del otro. Por las oportunidades que ofrece la vida pública, irá perdiendo el apego a su familia, su cultura, su pasado y sus orígenes.

Sin embargo, como ocurre en la mayoría de las autobiografías en que el protagonista siente la nostalgia de lo perdido, Richard Rodríguez recuerda su legado perdido con el español que oye en la librería: "Then nostalgia began. After years spent unwilling to admit its attractions, I gestured nostalgically toward the past.[...] One day I heard some Spanish academics whispering back and forth to each other, and their sounds seemed ghostly voices recalling my life" (1982:76). Con esta nostalgia empieza la conversión, "The Epiphanic Revelation" que recuerda al hijo pródigo de la Biblia, el que lo gastó (perdió) todo, pero que regresó hacia su padre. Al final del libro, Richard tiene una conversación con su padre quien le pregunta si va a volver a casa: "He asks if I am going home now too." (1982: 212). Esta interrogación indirecta tendría una doble interpretación: ya sea si Richard ha decidido quedarse finalmente con la familia, después de haberse separado de ella; ya sea si se resuelve a marcharse otra vez y definitivamente. 
Esta autobiografía nos hace captar también otra vertiente de la identidad que promueve Richard Rodríguez, la de ser diferente de los demás, pese a pertenecer a una etnia. En efecto, como la clase social marca mucho más que la raza, hay hispanos que se identifican más por su nivel social que por su origen étnico o su pertenencia a una raza, pues, "All Mexican-Americans certainly are not equally Mexican-Americans. [...] I was groomed for a position in the multiversity's leadership class" (1982: 161-162). Esta reflexión nos permite hablar de la identidad del Yo Richard Rodríguez que, como la de Richard Wright, es individual y hasta individualista: "But I write of one life only. My own" (1982:6). De todas formas, en esta autobiografía de infancia y de inmigrantes, el Yo está mucho más en relación con la clase que con la comunidad o la etnia.

A modo de conclusiones, establecemos un paralelo entre las cuatro autobiografías; las cuales ponen de realce la educación del niño en una familia y su integración social y cultural en Estados Unidos. Richard Wright, como niño negro, crece maltratado. Experimenta la segregación racial y carece de amor familiar; de ahí, la importancia de la educación para un niño, el amor familiar, los maltratos contra los niños y la discriminación racial. Con esta obra, Richard Wright se dirige más al lector implícito ("The Implied Reader") que es el blanco, pues el negro que escribe sobre la esclavitud se dirige al blanco para concienciarlo. Black Boy no es una autobiografía bilingüe ni bicultural, porque se ve el autor como estadounidense. Se separa de su tribu, de su comunidad y se libera contra el fundamentalismo de su enclave étnico-cultural. Es una autobiografía de infancia, pues es un relato de lo vivido por el autor durante la infancia y la adolescencia. Manifiesta una identidad individual(ista); por tanto es la obra, de concierto con James Olney (1993:217), "autoautography, o sea una auto autografía. Es aquí la idea de un Yo en su "self-realisation" y "self-affirmation", independientemente de la comunidad a la que pertenece, a pesar de que este "I" cuestiona la identidad de raza (la negra) y de clase (los pobres y oprimidos), como también la identidad individual cuestiona la colectiva. Por encima de todo, esta autobiografía, como es cualquier otra de minorías étnico-culturales, tiene una intención reivindicativa, doctrinaria y ejemplificante ya que el Yo se construye y se convierte en un ejemplo.

Con Alfred Kazin tenemos también una autobiografía de infancia. Es además de inmigrantes (judíos procedentes de Rusia), de minoría étnica (los judíos en los Estados Unidos) y bicultural (Yiddish e Inglés). La presencia del puente traduce el "hyphen" espacial que Kazin tiene que cruzar: "Beyond, beyond, beyond was the city" (1979:88). El uso repetitivo de "beyond" (más allá de) simboliza el sueńo y la ambición de Kazin de cruzar el puente y encontrarse en el otro lado, hacia lo que considera el paraíso. También, se trata de un "hyphen" identitario, porque el Yo encarna una doble identidad (judía y estadounidense) como Kingston (china y estadounidense); un Yo situado en un "between-world consciousness" o un "mid-zone mentality". Pero, Kazin aparece más en el proceso intercultural que bicultural, pese a que este Yo está unido a factores de raza (judía), clase (pobres y obreros) y grupo. Aquí, al contrario de lo que resalta en Hunger of Memory, pesa más el "We" que el "I", de ahí la identidad colectiva de este Yo.

El texto de Maxine Kingston es una autobiografía de minoría étnica, bicultural, de inmigrantes, de infancia y femenina basada en la ficción, con dos puntos de vista: el de la madre y el de la heroína. La hija y la madre son dos modelos de identidad femenina dicotómica: la esclava y la guerrera. Asistimos a una identidad unida a los factores de género (la suerte de las mujeres ofuscadas en una sociedad patriarcal) y de grupo, ya que la vida de la heroína (en los Estados Unidos) está también en la de su pueblo, lleno de patologías. El concepto de individualidad no existe aquí como en Hunger of Memory de Richard Rodríguez o Black Boy de Richard Wright, porque nos situamos en el contexto oriental donde el individuo aparece como un eslabón, ligado a la sociedad, al otro, 
y no puede escaparse fácilmente sin dejar plumas; de ahí que se pueda ver que Kingston intenta ser estadounidense sabiéndose genéticamente china, ser mujer liberada sabiéndose subyugada, contar cosas sabiendo que debe guardar silencio.

Con la obra de Richard Rodríguez resalta el desacuerdo entre el Yo y sus padres respecto de su educación y su asimilación. Este chicano está a favor de los efectos de la anglosajonización producidos por el sistema educativo estadounidense. Piensa que las minorías deben aprovecharse del sistema educativo dominante en los Estados Unidos. "Browning of America" es una expresión acuñada por el autor para hablar del mestizaje de las identidades culturales, raciales y étnicas en los EE.UU. durante los siglos XX y XXI. Para el autor, esta expresión denota más el color moreno como símbolo de la mezcla en los EE.UU. o, si se quiere, la gran diversidad étnica, racial y cultural. De manera inherente, se puede observar la gran expansión demográfica cada vez mayor de las minorías en los EE.UU.

Richard Rodríguez denuncia la acción afirmativa y la educación bilingüe, dos proyectos muy a menudo defendidos por los otros chicanos. En efecto, Rodríguez piensa que esos dos conceptos son anti-asimilacionistas y alienantes, en detrimento de los grupos étnicos como es el caso de los chicanos y afro-estadounidenses. Está en contra de la educación bilingüe porque piensa que de no haber sido forzado a aprender inglés, no hubiera sido capaz de alcanzar una personalidad pública y ser un miembro productivo en esta sociedad, con todos los beneficios que eso acarrea. Por lo tanto, celebra en esta obra el monolingüismo y el monoculturalismo como formas de expresión.

La acción afirmativa conocida también como "la discriminación positiva" se refiere a las medidas tomadas para promover la educación o el empleo para los grupos no-dominantes (gente de color o mujeres) histórica y socialmente marginados y discriminados. Permite a las instituciones públicas como las universidades, los hospitales, la policía, etc., tomar en cuenta la representatividad de las minorías. Se realiza mediante los programas de reclutamiento a favor de los sociopolíticamente desfavorecidos ("desadvantaged groups") y en algunos casos, a través del uso de las cuotas. Los oponentes a la acción afirmativa ven aquí otra forma de discriminación (especialmente las razas mayoritarias y gente como el propio Richard Rodríguez). Esta autobiografía nos parece entonces la leyenda de un personaje que transciende las barreras humanas, espaciales y temporales para controlarse a sí mismo, viviendo en un vaivén espacio-mental, aún anglosajonizándose.

Richard Rodríguez comparte la misma experiencia que Alfred Kazin en $A_{-}$Walker in the City. Al respecto, escribe:

I remember reading "A Walker in the City" one summer night when I was a boy in the Central Valley of California. I was a fool of generation and several thousand miles away from Kazin's New York. There was Spanish in my house, not Yiddish. But in that wonderful way that books allow, one life sharing with another, I walked with Alfred Kazin through Brooklyn[...] I remember Alfred Kazin, a boy in Brooklyn, myself a boy as a reader, the two of us intent on assuring an American voice, on joining our voices to the chorus that has sounded through generations before $\mathrm{us}^{2}$.

Rodríguez y Kazin son asimilacionistas. Ambos expresan la lucha entre las lenguas y entre "them" (estadounidenses de la mainstream) y "us" (nosotros, las minorías). Para los dos autobiógrafos, la

2. Richard RODRIGUEZ, "Cultural Legacy” en Essays and Dialogues, 30 de agosto, 1998. http://www.pbs.org/ newshour/essay/august98/Rodriguez. 
lengua de origen se convierte en "private language" mientras que el inglés es finalmente considerado como "public language" y empiezan sus obras respectivas con la alusión a la literatura.

\section{Referencias bibliográficas}

BOELHOWER, W., "The making of Ethnic Autobiography in the United States" American Autobiography: Retrospect and prospect, The U of Wisconsi Press, 1991, pp. 123-141.

BORREGO SILVA, C., "Nuevas Comunidades, Identidades y Energías: la novela de Rudolfo Anaya, Bendíceme, Ultima”, Literatura Chicana. III International Conference on Chicano Literature, 2123 de mayo, 2002. Universidad de Málaga. Webdeptos.uma.es/filifa/chicana/índices.htm.

Carlos CASTILLA DEL PINO, C., Teoría del personaje, Alianza Editorial, Madrid, 1989.

KAZIN, A., A Walker in the City, Harcourt, New York, 1979.

KINGSTON HONG, M., The woman warrior: Memoirs of a Girlhood among Ghosts, Pan Macmillan, London, 1977.

LEJEUNE, P., Le Pacte autobiographique, Seuil, Paris, 1996.

OLNEY, J., "The Value of Autobiography for Comparative Studies: African vs. Western Autobiography" en Andrews (ed.), African American Autobiography: A Collection of Critical Essays, Prentice-Hall, New Jersey, 1993, pp. 212-223.

RODRÍGUEZ, R., Hunger of Memory: The Education of Richard Rodriguez, Bantam Books, New York, 1982.

RODRÍGUEZ, R., "Cultural Legacy” en Essays and Dialogues, 30 de agosto de 1998, http://www. pbs.org/newshour/essay/august98/rodriguez.

SHOHAT, E. y STAM, R., Unthinking Eurocentrism. Multiculturalism and the Media, Routledge, New York, 1994.

SONG, A., "Perspectiva de la enseñanza de la cultura hispánica y propuestas didácticas para la interculturalidad en el aula de español en Corea del Sur", FIAPE. IV Congreso Internacional: la enseñanza del español en un mundo intercultural. Jornadas Pedagógicas. Santiago de Compostela, 17-20 de abril, 2011.

WRIGHT, R., Black Boy, Vintage Classics, London, 2007. 